\title{
Reflexões de professores de inglês em formação inicial sobre o uso de novas tecnologias $^{1}$
}

\author{
Reflections of English Teachers in Initial \\ Training on the Use of New Technologies
}

Janara Barbosa Baptista*

Universidade Estadual Paulista

São José do Rio Preto - São Paulo / Brasil

RESUMO: Este artigo objetiva investigar as reflexóes de professores de inglês em formação inicial sobre o uso de novas tecnologias para o ensino e aprendizagem de línguas, após a realização de uma disciplina a distância de um curso de Licenciatura em Letras, que enfoca a discussão desse tema. $\mathrm{O}$ corpus utilizado para o seu desenvolvimento é composto por produçôes textuais escritas realizadas pelos alunos no âmbito dessa disciplina. Os resultados obtidos possibilitam observar que a maior parte dos alunos envolvidos na pesquisa avalia a experiência na disciplina como positiva, uma vez que percebem a importância da reflexão sobre o uso de novas tecnologias no ensino e aprendizagem de línguas estrangeiras, na realidade tecnológica em que vivemos.

PALAVRAS-CHAVE: novas tecnologias, ensino e aprendizagem de línguas, letramento digital.

ABSTRACT: The aim of this paper is to investigate the reflections of English teachers in initial training on the use of new technologies for teaching and learning languages after undergoing an on-line discipline, of a Teacher Education Course focused on the discussion of this theme. The corpus used for its development consists of written textual productions composed by the students in the context of this discipline. The results obtained show that most of the students involved in the research assessed the experience in the discipline as positive, since they realize the importance of reflection on the use of new technologies in teaching and learning foreign languages in the technological reality in which we live.

KEYWORDS: new technologies, language learning and teaching, digital literacy.

\footnotetext{
* janarabaptista@yahoo.com.br

${ }^{1}$ Processo no 2012/04993-1, Fundação de Amparo à Pesquisa do Estado de São Paulo (FAPESP).
} 


\section{Introdução}

Como não poderia deixar de ser, o ensino de línguas, assim como outras áreas, tem sido fortemente influenciado por novas tecnologias que transformam o mundo, contínua e rapidamente, e que desafiam a forma tradicional de educação e o papel de professores e alunos (MATTOS, 2011).

Braga e Costa (2000) afirmam que o computador otimiza o tempo de preparação de atividades complementares pelo professor que, com o advento $\mathrm{e}$ expansão da internet, passou a ter acesso a um gigantesco banco de dados construído coletivamente na rede. Isto possibilita, por exemplo, o acesso a jornais e revistas estrangeiras e sites específicos para o ensino de línguas, que podem ser utilizados como complementação dos exercícios realizados em sala de aula.

Da mesma forma, de acordo com as autoras, o aluno não está mais restrito ao insumo de língua estrangeira, propiciado apenas pelo material didático selecionado e utilizado pelo professor em sala de aula. Atualmente, ele também tem acesso a sites específicos para a aprendizagem de línguas que possibilitam um estudo independente. Além disso, ele pode interagir, através de uma variedade de ferramentas, com qualquer pessoa ao redor do mundo sobre um interesse em comum e com menor pressão comunicativa, já que, muitas vezes, essa comunicação é escrita.

Contudo, o aumento de autonomia e a alteração das funções de professores e alunos trouxeram problemas que devem ser considerados. Além de ter acesso às novas tecnologias, eles precisam, dentre outras exigências, saber encontrar e selecionar informaçōes válidas e confiáveis, nesse mar de informaçōes na internet, através de ferramentas de busca, o que caracteriza uma nova prática social e exige de ambos letramento digital.

A necessidade de realinhar a formação de professores e alunos frente à realidade tecnológica atual e seus reflexos na educação é prevista pelos documentos oficiais. Como apresentado por Paiva (2012), o Plano Nacional de Educação (2001) e as Diretrizes Curriculares Nacionais para a Formação de Professores da Educação Básica (2002) preveem a preparação dos professores nos cursos de formação para o uso de novas tecnologias de informação e comunicação, e a integração delas em suas práticas docentes.

Em razão da urgente necessidade de reformulação das práticas educacionais e das mudanças que isso acarreta para o professor, este artigo tem como objetivo verificar e analisar as reflexões de professores de língua estrangeira (inglês), em formação inicial, sobre o uso de novas tecnologias após a realização de uma disciplina a distância, de um curso de Licenciatura em 
Letras, que tem como eixo o uso de tecnologias para o ensino e aprendizagem de línguas.

Enfocamos, assim, a formação inicial de professores e ressaltamos a relevância para a formação tecnológica desses profissionais, para que eles tenham contato com discussões sobre o uso de novas tecnologias na educação desde a graduação e cheguem às salas de aula, de diferentes contextos, mais preparados para lidar com essa nova realidade.

\section{Fundamentação teórica}

Segundo Bax (2003, p.23), o modo como uma inovação é aceita no seu novo domínio pode ser considerado através do conceito de normalização, o qual é relevante para qualquer tipo de inovação e refere-se "ao estágio quando a tecnologia se torna invisível, embutida na prática diária e, portanto, normalizada" ${ }^{2} \mathrm{Na}$ educação, esse é o caso de tecnologias como o livro, a lousa e o giz, que estão integradas à sala de aula e já não são mais reconhecidas como tecnologias por professores e alunos.

Por outro lado, nessa mesma área, esse conceito ainda não se aplica às novas tecnologias de informação e comunicação, tal como o computador. Ao contrário, essas tecnologias ou são colocadas em pedestais e entendidas como a solução para problemas ou são rebaixadas e consideradas como um mal que causará danos (BAX, 2011). Para Bax (2011), é preciso se afastar dessa discussão simplista, popular e polarizada, e entender a tecnologia com suas vantagens e desvantagens, considerando outros fatores que se relacionam, tanto socioculturais como técnicos, tais como o professor e a instituição, e que podem ser potencialmente significativos.

Por essa razão, apenas o investimento em equipamento, mas não na preparação de profissionais para utilizá-lo, não é sinônimo de melhoria ou mudança (BAX, 2003; VIEIRA, 2010; BAX, 2011). A inserção da tecnologia na educação não é suficiente para que o trabalho seja desenvolvido com sucesso, visto que os professores precisam ter a habilidade técnica para usar a tecnologia (WARSCHAUER, 2004; HUBBARD; LEVY, 2006; REINDERS, 2009) e também saber como utilizá-la de forma pedagógica (KESSLER, 2006; HUBBARD; LEVY, 2006; SANTOS, 2009). Têm-se, então, como afirma Vieira (2010), duas facetas no longo processo de apropriação das novas tecnologias.

\footnotetext{
${ }^{2}$ No original: "[...] refers to the stage when the technology becomes invisible, embedded in everyday practice and hence 'normalised'."
} 
Braga e Costa, em artigo de 2000, apontavam a necessidade de uma melhor teorização para o uso do computador como ferramenta de aprendizagem de línguas, em razão da nova realidade que esse uso representa, e acreditamos que essa necessidade ainda se faz presente 14 anos depois, principalmente no que se refere à prática do professor.

Esse profissional envolvido no processo educativo, assim como outros, teve seu papel alterado e passou a ter diferentes e novas atribuições em razão da inserção e constante transformação das novas tecnologias de informação e comunicação, na sociedade e na educação. Como citado por Motteram e Stanley (2011), por exemplo, os ambientes de aprendizagem deixaram de ser apenas físicos e representados pela sala de aula e passaram a ser também virtuais, o que exige preparação e orientação diferentes por parte do professor de línguas.

Além disso, o professor, caracterizado como "imigrante digital", encontra em sala de aula alunos considerados "nativos digitais" (PRENSKY, 2001, p.1), ou seja, nasceram imersos em um mundo digital e são falantes nativos da língua desse mundo. Consequentemente, essa diferença gera discordâncias na educação ao se ter professores imigrantes digitais, ensinando alunos que falam outra língua e que têm as novas tecnologias como uma extensão de seus corpos e mentes.

Desse modo, Warschauer (2002) levanta a necessidade de professores com conhecimento, habilidade e atitude para desenhar, adaptar e planejar o uso de tecnologias na sala de aula que seja apropriado para o contexto local. Essa ideia vai ao encontro da afirmação de Bax (2011) de que o professor precisa questionar se a tecnologia é de fato necessária e útil em determinado contexto. Warschauer (2002) ainda assevera que o professor precisa ajudar o aluno não apenas a usar tecnologia como ajuda institucional, mas também a usá-la como meio de comunicação, pesquisa e produção de conhecimento.

Nota-se, assim, a necessidade, já não tão recente, de repensar o processo de formação de professores em relação à tecnologia, em razão da exigência atual que enfatiza um profissional autônomo, reflexivo e com capacidade para inovação. Sendo assim, como apontam Souza, Silva e Saito (2009), a formação do professor apoiada apenas na cultura do texto impresso não é mais suficiente para lidar com novas tecnologias.

De acordo com Paiva (2012), a preocupação no que concerne à formação tecnológica é crescente. No entanto, as ações em direção a essa formação ainda são isoladas e apenas alguns profissionais têm a iniciativa 
de adotar recursos tecnológicos em suas práticas pedagógicas e de difundir essa adoção. A autora defende, então, a inserção das novas tecnologias de informação e comunicação na formação de professores de línguas, por conta da crescente demanda dessas tecnologias em cursos presenciais e do aumento de cursos e disciplinas mediados por computador.

Outros autores, tais como Braga e Costa (2000), Buzato (2001), Kessler (2006), Imbernom-Pereira (2009), Souza, Silva e Saito (2009), Bohn (2010), Paiva (2010) e Silva (2012 são a favor de uma disciplina voltada para capacitação do professor em formação, no uso do computador e outras novas tecnologias, através de discussões e reflexões, possibilitando o acesso, durante a graduação, aos princípios que norteiam e capacitam o futuro professor a utilizar os novos recursos e a orientar seus alunos a fazê-lo.

Alguns estudos recentes apontam para essa necessidade. A exigência de letramento digital na formação de professores fica clara, por exemplo, na pesquisa de Souza, Silva e Saito (2009), na qual os alunos investigados relatam os benefícios da discussão teórica sobre o uso dos recursos do computador realizada em uma disciplina voltada ao uso do computador no ensino de línguas.

A insegurança dos alunos, por sua vez, é mencionada por Egbert (2006) e Peters (2006) ao afirmarem que muitos não se sentem preparados para integrar tecnologia às suas futuras aulas. No estudo realizado por Peters (2006) notouse, ainda, que apenas um curso isolado não foi suficiente para que os alunos entendessem tecnologia como um componente integrado ao programa. Por essa razão, o autor sugere a integração da abordagem e o uso da tecnologia ao longo do curso de formação. Da mesma forma, Kessler (2006) afirma que, em geral, professores não dão continuidade ao uso de tecnologia em sala de aula após o término de cursos de treinamento, sugerindo um impacto pequeno desses cursos no modo como pensam.

Na pesquisa de Vieira (2010), a qual foca o programa de capacitação do Proinfo Integrado, os dois professores que não se engajaram em processo de formação tecnológica integram apenas tecnologias tradicionais (lousa, giz, livro didático, dentre outros) ao mediar suas atividades pedagógicas. Já o professor que participou dos três cursos oferecidos pelo programa substituiu as tecnologias tradicionais por webtecnologias, que não eram antes exploradas por ele, e integrou um número maior delas à sua prática.

Desse modo, segundo a autora, o engajamento em atividade de formação tecnológica possibilita que o professor sinta-se mais seguro para 
utilizar aparatos webtecnológicos e promova mudança na sua prática e na sua visão sobre o papel do aluno, já que se passa de estratégias em que o aluno é um receptor passivo de informações para estratégias em que ele atua como produtor ativo de conhecimento.

Essa ideia vai ao encontro da afirmação de Warschauer (2004) de que o estudo de línguas, atualmente, não tem como objetivo apenas a aquisição de um sistema interno, mas a capacidade de usar a língua para ter um impacto real no mundo, o que pode ser alcançado, a nosso ver, através de um professor que tenha tido uma formação tecnológica nesse sentido, como a abordada por Vieira (2010), e que será capaz de preparar o aluno para essa nova exigência.

Defendemos, ainda, a ideia de Paiva $(2010,2012)$ de que já está na hora de pensar em modelos institucionalizados de formação para o uso de tecnologias, inclusive nas ações de estágios, para que não haja apenas iniciativas isoladas nesse sentido e para que os esforços não fiquem restritos a um pequeno componente no currículo.

A autora propõe um modelo de formação de professores que envolva administração, ensino, pesquisa e extensão com base em Reinders (2009) e em sua própria experiência, de onde destacamos a sugestão de que "disciplinas específicas devem ser oferecidas, tanto para graduandos como para pósgraduandos, de forma a levar os futuros docentes a não apenas usar a tecnologia, mas a refletir sobre as práticas sociais mediadas por ela”. (PAIVA, 2012, p.228)

Associado a isso, ressaltamos também, como proposto pela autora, a importância de os professores formadores incorporarem as novas tecnologias em suas atividades docentes, para difundir esses recursos e incentivar os futuros professores a se apropriarem deles, já que apenas falar sobre as novas tecnologias não é suficiente e é preciso que o corpo docente dê o exemplo de seu uso.

Acreditamos que a inserção de uma disciplina voltada para a formação tecnológica já na graduação pode contribuir para que o futuro professor assuma uma postura crítica e reflexiva, não apenas sobre a integração e exploração de tecnologias em atividade de ensino e aprendizagem (VIEIRA, 2010), mas, também, sobre estratégias de ensino que possibilitem "a construção de conhecimento disciplinar de forma autônoma e integrada" (VIEIRA, 2010, p.101). De acordo com Paiva (2012), autonomia é um conceito chave, já que as tecnologias evoluem e mudam rapidamente, o que exige que tanto alunos como professores aprendam a utilizá-la de forma mais autônoma.

É possível, ainda, que essa reflexão e autonomia estimuladas na formação inicial contribuam para amenizar aspectos negativos de uma realidade em que, 
segundo Felix (2008 apud VIEIRA, 2010), o professor continua utilizando novos recursos tecnológicos de modo tradicional (alunos recebendo e consumindo conhecimento de forma passiva), em razão da sua postura também tradicional, que dificulta a inserção das novas tecnologias com o intuito de propor a produção ativa de conhecimento por parte do aluno.

Assim, seguindo o pressuposto citado por Paiva (2012, p.215) de que "os computadores não vão substituir os professores, mas os professores que usam computadores vão substituir os que não o fazem", salientamos que já é mais do que sabido que uma formação tecnológica é urgente e necessária, em razão das mudanças que a sociedade e, por consequência, o campo educacional vêm sofrendo. A partir da formação inicial é possível que se trilhe o caminho em direção a conectar a escola e a prática do professor à realidade digital em que vivemos.

\section{Metodologia}

A presente pesquisa caracteriza-se como uma pesquisa qualitativa, de base etnográfica (BURNS, 1999), e enfoca um contexto universitário de um curso de Licenciatura em Letras (português e inglês), com duração de quatro anos e regime anual de aulas, de uma faculdade particular paulista.

Os dados foram coletados durante a disciplina a distância "Projeto Interdisciplinar III" do $3^{\circ}$ ano do curso, que faz parte de um conjunto de disciplinas ("Projeto Interdisciplinar I" e "Projeto Interdisciplinar II", do 1o e $2^{\circ}$ anos do curso, respectivamente) que objetivam promover a regência de cursos interdisciplinares que se apoiem em temas abordados nas diversas disciplinas do curso de Letras.

A disciplina "Projeto Interdisciplinar III", especificamente, pretende que o futuro docente avalie criticamente o uso de novas tecnologias no processo de ensino e aprendizagem de línguas, e incorpore esses recursos nas aulas desenvolvidas para o estágio de regência de língua portuguesa e língua inglesa. O foco deste artigo, contudo, é apenas o estágio de língua inglesa.

As aulas da disciplina eram ministradas por esta professora-pesquisadora, através da área específica para as disciplinas a distância no site da faculdade. Semanalmente, textos eram postados e discutidos em um fórum virtual e, então, os alunos eram orientados a realizar atividades que se relacionavam aos textos abordados.

Como atividade de encerramento do primeiro e segundo semestres da disciplina, em 2012, os alunos realizaram produçóes textuais escritas, as quais compóem o corpus utilizado para o desenvolvimento deste artigo. Essa atividade 
tinha como objetivo provocar a reflexão dos alunos sobre as experiências que haviam tido naqueles semestres em relação à disciplina e ao estágio de regência, e seus textos escritos deveriam ser postados para a professora-pesquisadora na área da disciplina dentro do prazo estabelecido nas orientações.

Ao todo, 17 dos 24 alunos do $3^{\circ}$ ano do curso naquele ano produziram os textos reflexivos, totalizando 27 textos produzidos nos dois semestres: 17 no primeiro e 10 no segundo. Alguns participantes produziram, assim, textos em apenas um dos semestres.

Optamos por analisar os dados das duas produções escritas conjuntamente, uma vez que o objetivo é levantar e analisar as reflexóes dos participantes ao longo da disciplina, sem comparar as reflexôes feitas em diferentes momentos. Além disso, a maior parte dos temas mencionados nos dois momentos é semelhante, o que deixaria a análise repetitiva se fosse feita separadamente.

Após a coleta do corpus, então, as produções escritas foram analisadas. Primeiramente, os dados foram categorizados e, em seguida, discutidos e analisados, com o objetivo de levantar as reflexôes mais frequentes dos professores em formação sobre o uso de novas tecnologias após a realização da disciplina.

\section{Análise dos dados}

Nesta seção, os dados coletados na disciplina "Projeto Interdisciplinar III" são descritos, interpretados e analisados. Para melhor organização e compreensão da análise, apresentamos os tópicos mais mencionados pelos participantes nas duas produçóes de cada semestre.

Primeiramente, os participantes ressaltam a relevância do tema abordado na disciplina, em razão do espaço que as novas tecnologias ocupam nas diversas esferas de nossa vida e da necessidade de conectá-las também à educação e à formação de professores, como fica claro nos excertos ${ }^{3}$ a seguir:

Excerto 1 - Participante $\mathrm{A8}^{4}$

Ao compreender a dinâmica dessa disciplina, consigo enxergar de forma bastante clara sua importância na EDUCAÇÃO atual.

\footnotetext{
${ }^{3}$ Os excertos foram extraídos dos textos produzidos pelos alunos e procurou-se não alterar a redação do texto original.

${ }^{4}$ Para preservar a identidade dos participantes desta pesquisa, serão utilizados letras e números para se referir a cada um deles.
} 


\section{Excerto 2 - Participante A3}

Assim, como pudemos observar também com o Projeto Interdisciplinar III, diversos estudos e experimentos acerca da inserção dessas novas tecnologias ao ensino têm surgido. E nada mais coerente num mundo onde as novas tecnologias transcendem em todas as faces da vida.

\section{Excerto 3 - Participante A3}

Projeto Interdisciplinar III foi o mais proveitoso e o que mais me permitiu refletir e compreender assuntos sobre a minha atual e futura profissão que antes eu jamais considerava.

Ademais, quatro participantes percebem que, embora tenham conhecimento sobre algumas novas tecnologias e as utilizem em diversas atividades do seu cotidiano, eles nunca haviam refletido sobre como essas tecnologias poderiam ser utilizadas em sala de aula para fins pedagógicos. Nota-se, também no excerto 3, que a participante em questão afirma que a disciplina discutiu questóes que antes ela não considerava.

Isso corrobora a ideia de autores, tais como $\operatorname{Bax}(2003,2011)$, Warschauer (2004), Hubbard e Levy (2006), Reinders (2009), Kessler (2006), Santos (2009) e Vieira (2010), de que apenas a inserção da tecnologia nas escolas não é suficiente para modificar a prática do professor, já que o seu uso não depende apenas de conhecer e saber lidar (ou não) com a tecnologia em questão.

Acrescentamos também que não é suficiente pressupor que professores em formação, mais jovens, que fazem uso de novas tecnologias em seu cotidiano, saberão utilizá-las pedagogicamente. Todos os participantes que apontaram que não sabiam como utilizar as novas tecnologias trabalhadas na disciplina (redes sociais, blog, podcast, wiki, dentre outras) para fins pedagógicos tinham, na época em que os textos foram redigidos, 21 anos, ou seja, apesar de jovens e de estarem em constante contato com tecnologias, eles não conseguem necessariamente pensar em um uso pedagógico dessas ferramentas:

\section{Excerto 4 - Participante A7}

[...] antes das leituras e antes das práticas não tinha noção de como utilizar os meios tecnológicos para trabalhar em sala de aula.

\section{Excerto 5 - Participante A16}

Apesar de não sermos analfabetos digitais e dominarmos uma parte das novas tecnologias, não sabíamos como seria possível usá-la em um contexto educacional, para se atingir os objetivos desejados. 
Oito participantes mencionam ainda a importância de se considerar o contexto e o aluno para que o ensino seja coerente com a realidade digital em que ele vive, com o intuito de envolvê-lo na aprendizagem, interagir com ele e mediar conhecimento, como se percebe nos excertos a seguir:

\section{Excerto 6 - Participante A16}

[...] como vimos, os alunos de hoje são nativos tecnológicos e cada vez mais tem a necessidade de ver esse mundo tecnológico incluso no processo de aprendizagem.

\section{Excerto 7 - Participante A8}

Ao considerarmos que as crianças tem muito mais facilidade de aprender sobre as novas tecnologias, os professores devem ter conhecimento das mesmas, como forma de interagir com essas crianças e jovens e, mediar informações disponíveis e atualizadas virtualmente.

Desse modo, a disciplina pode ter ao menos iniciado a percepção desses futuros professores de que é preciso avaliar o uso da tecnologia para o contexto local (WARSCHAUER, 2002) e questionar se ela é apropriada, útil e necessária (BAX, 2011). Ao considerar ainda a realidade dos alunos, eles podem passar a refletir sobre as maneiras que a tecnologia pode ser utilizada dentro e fora da sala de aula, para que o aluno se comunique e produza conhecimento no mundo atual (WARSCHAUER, 2002, 2004).

Outra questão mencionada pelos participantes é o papel que o professor passa a assumir ao considerar alunos nativos digitais (PRENSKY, 2001) e o contexto local em um processo de aprendizagem não mais caracterizado como tradicional, mas que abarca a construção e produção de conhecimento na língua estrangeira, por parte do aluno, através de ferramentas tecnológicas.

Segundo os participantes, o professor deixa de ser o detentor de conhecimento e passa a ser um mediador de conhecimento, responsável por apresentar ao aluno algumas possibilidades atuais de aprendizagem e orientálo na navegação por essas possibilidades, devendo estar, assim, sempre atualizado e em constante busca por outras inovaçóes. Ressaltamos que a noção de professor mediador não é nova e não surge com a discussão sobre novas tecnologias no ensino de línguas, mas os participantes parecem perceber como a ideia de detenção do conhecimento por parte do professor não mais se aplica a uma realidade em que as paredes da sala de aula foram transpostas e o aluno navega pelas redes de conhecimento da internet. 
Essa ideia vai ao encontro da afirmação de Warschauer (2002) de que é preciso que os professores tenham conhecimento, habilidade e atitude para planejar o uso de tecnologias na sala de aula com o intuito, dentre outros, de orientar o aluno nessa navegação e nas escolhas e perigos que a internet oferece. Sabemos, contudo, que os cursos de formação de professores e a própria organização e estrutura das escolas ainda não dão o respaldo necessário para que o professor esteja preparado para isso, e segue-se com açóes isoladas, como afirma Paiva (2012), ou tradicionais, como afirma Felix (1998 apudVIEIRA 2010), que ajudam a corroborar a ideia de que as tecnologias representam mais um fardo para o professor.

Os excertos a seguir exemplificam a opinião dos cinco professores em formação que mencionaram o papel atual do professor:

\section{Excerto 8 - Participante A6}

Aprendi também que o professor, independentemente de lecionar numa escola pública ou particular, deverá estar capacitado para direcionar a atenção de seus alunos para as pesquisas de seus trabalhos escolares na Internet em qualquer um dos muitos sites de busca, blogs, etc., fazendo-os perceber que o intuito é fazê-los crescer sócio, cultural e profissionalmente, independente da escola ser pública ou particular.

\section{Excerto 9 - Participante A4}

O projeto interdisciplinar, neste semestre, trouxe novos conhecimentos voltados para a tecnologia, mostrou que o professor não precisa necessariamente ficar preso à sala de aula, ele deve inovar, fazer parte do mundo do aluno, para que a aprendizagem seja instigadora. Com isso o aluno se tornará mais independente e o professor será o mediador do ensino, e não mais, o detentor de todo o saber, havendo assim troca de informações.

\section{Excerto 10 - Participante A10}

Surge então outra obrigação do professor; a de orientá-los a fazer um uso mais construtivo de todas as informaçōes as quais estão expostas no dia-a-dia, e, assim, ajudá-los a fazer da tecnologia uma aliada na construção de um conhecimento mais estruturado e permanente.

\section{Excerto 11 - Participante A6}

Percebi que a tecnologia está presente em todos os segmentos de nossa sociedade, e que podemos integrá-los à prática do processo de ensino/ aprendizagem, do qual o professor se torna mediador do ensino e não mais o detentor do saber. 
Além disso, como mostram os excertos a seguir, dez participantes afirmam em suas produções que as discussões e atividades desenvolvidas ao longo da disciplina tiveram significativa importância em suas formações, uma vez que elas possibilitaram o contato com tecnologias que não eram conhecidas, a percepção de como essas e outras tecnologias com as quais já estavam familiarizados poderiam ser utilizadas com fins pedagógicos e a reflexão sobre questóes atuais que envolvem o uso de novas tecnologias, a educação e o papel do professor. No excerto 15 , ainda, uma aluna menciona que já incluiu uma nova tecnologia na sua prática como professora e obteve resultados positivos:

\section{Excerto 12 - Participante A16}

Uma formação como essa é extremamente importante para os profissionais da nossa área, para que possamos caminhar, mesmo que a passos lentos, a uma reforma no sistema educacional do nosso país, e, ainda na nossa geração, possamos ter o prazer de contemplar essa mudança e desfrutar de seus benefícios.

\section{Excerto 13 - Participante A13}

Em relação às discussões sobre as novas tecnologias, me tornei mais crítica, sempre associando com a realidade em que vivemos, esse projeto propôs textos que me fizeram refletir e me tornar mais crítica com a questão de novas tecnologias.

\section{Excerto 14 - Participante A3}

Não somente para minha formação profissional, mas também para minha vida, acredito que a disciplina foi extremamente proveitosa: conhecemos ferramentas novas, aprendemos a utilizar ferramentas conhecidas a favor do ensino e discutimos ideias acerca do tema.

\section{Excerto 15 - Participante A3}

Considerando na prática os conceitos estudados, estou certa de que obtive aulas mais criativas e melhor executadas graças à disciplina; mesmo tendo pouca experiência na minha área, acredito que tive um ótimo desempenho e o fator de incluir nas aulas filmes/vídeos, músicas e até ter o Facebook como um aliado (já que criei um grupo para a turma) com certeza foram um grande diferencial e transformou as aulas em um momento muito mais divertido do que poderia ser.

Por outro lado, uma única participante apontou aspectos negativos do uso de novas tecnologias e mostrou-se desmotivada. Todos os outros 
participantes ressaltaram apenas, como foi possível perceber até o momento, a necessidade do uso dessas tecnologias e os benefícios que elas podem trazer, o que nos chama a atenção e nos faz questionar se eles ainda polarizam a discussão sobre esse assunto e colocam a tecnologia num pedestal (BAX, 2011) mesmo depois da realização da disciplina "Projeto Interdisciplinar III".

Embora essa participante, assim como os outros, reconheça a importância das novas tecnologias, ela ressalta os obstáculos enfrentados pelo professor e a carga extra que esse uso acrescenta na sua prática, aparentemente salientando apenas o outro polo desse uso:

\section{Excerto 16 - Participante A11}

Percebi que a elaboração de atividades usando recursos tecnológicos gera um certo esforço do professor, que se depara com vários obstáculos, dentre eles estão: tempo, computadores em bons estados, boa disposição da escola e sua coordenação, disciplina dos alunos e, o mais importante, o conhecimento técnico do professor sobre o assunto. [...] Apesar de eu saber da diferença que faz esses meios de informação na vida do aluno, não gostei nem um pouco de estar na pele do professor na hora de elaborar essas aulas. [...] Sei que isso serviu para me mostrar que eu preciso procurar mais por informaçôes, e me dedicar aos meios tecnológicos, pois eles estão presentes em todas as áreas do conhecimento [...].

Contudo, cinco dos dez alunos participantes que produziram os textos no $2^{\circ}$ semestre mencionam dificuldades enfrentadas durante o estágio de regência, momento em que eles deveriam fazer uso das novas tecnologias que estavam sendo discutidas na disciplina, o que demonstra a importância da prática na formação do futuro professor, aspecto que também foi percebido por eles:

Excerto 17 - Participante A10

Durante o estágio de regência pudemos colocar em prática o que nos foi ensinado em sala de aula, e constatar o quanto é importante para alunos e professores a utilização de tais ferramentas.

\section{Excerto 18 - Participante A16}

A prática que a disciplina nos proporcionou foi decisiva para que essas questôes fossem não só aprendidas, mas refletidas pela nossa própria experiência.

Smagorinsky, Cook e Johnson (2003) afirmam que não se contempla como uma pessoa aprende ao dar foco para a teoria e a prática, e especialmente para sua separação, visto que, para os autores, o desenvolvimento de uma 
abordagem de ensino está em relação dialética com o desenvolvimento de uma concepção de ensino. Nesse ponto, é possível traçar um paralelo com as pesquisas de Peters (2006), Kessler (2006) e Souza, Silva e Saito (2009), mencionadas anteriormente, que apontam a relevância da relação teoria e prática na formação de professores para o uso de novas tecnologias.

Para Vieira (2012), os professores devem assumir uma posição crítica no que concerne ao uso e à exploração de tecnologias em salas de aula de língua estrangeira e, para isso, é necessário, de acordo com a autora, que os programas de formação possibilitem momentos de prática e reflexão sobre elas, para que sejam formados professores reflexivos e para que o conhecimento cotidiano do profissional seja reconhecido e valorizado. A disciplina "Projeto Interdisciplinar III" vai ao encontro dessa ideia, já que objetiva fornecer o espaço para que futuros professores reflitam sobre novas tecnologias, através da relação dialética entre teoria e prática.

Foi através da prática nos estágios de regência que os participantes puderam considerar o uso das novas tecnologias para as aulas de língua e, principalmente, avaliar o seu uso, necessidade e utilidade, de acordo com o contexto local e os alunos em questão, considerando as discussões realizadas na disciplina, o que contribui para a percepção e análise das vantagens e desvantagens que envolvem o uso de novas tecnologias na sala de aula de língua. Os excertos abaixo exemplificam as dificuldades mencionadas pelos participantes durante os estágios de regência:

\section{Excerto 19 - Participante A10}

Contudo, ainda no estágio de regência, vivenciamos a dura realidade do ensino no Brasil, realidade essa que já tínhamos ouvido falar nos textos estudados por essa disciplina, e nos deparamos com salas de aula precárias, sem equipamentos que pudessem levar o aprendizado dos alunos a outro nível. Ao nos depararmos com tantas dificuldades, ainda tentamos utilizar ferramentas digitais que estão ao nosso alcance em casa, criando páginas da sala de aula no Facebook, mensagens de texto via celular, fóruns, e as tão conhecidas pesquisas como tarefa, mas ainda assim, encontramos alguns alunos que não conseguem se beneficiar com esse projeto, visto que alguns não possuem computadores, nem telefone celular, e nem, tão pouco, interesse suficiente para se autodoutrinar a estudar em ambientes em que estão acostumados a encontrar lazer. Para que todos tivessem um aproveitamento adequado e homogêneo, seria necessária a orientação e o estímulo constante do professor em sala de aula; pelo menos no começo, até que os alunos se habituassem a utilizar as ferramentas digitais e informações disponíveis com mais responsabilidade de consciência. 


\section{Excerto 20 - Participante A4}

Infelizmente não obtive a oportunidade de trabalhar com tecnologia em meus estágios, pelo fato de que as escolas estaduais ainda não possuem computadores o suficiente para os alunos e muitos deles não têm acesso a essa tecnologia.

\section{Excerto 21 - Participante A6}

Apenas lamento não poder usar de uma maneira mais ampla a tecnologia em meus estágios, visto que as escolas nas quais foram realizados estes não possuem um número ideal de computadores, que pudessem ser usados por todos os alunos, levando em conta que muitos desses alunos não possuem computadores em suas residências. Sugeri que buscassem uma Lan House para fazer pesquisas e enriquecer o próprio conhecimento.

Por fim, as três participantes do grupo que estavam na faixa etária de 30 e 40 anos afirmaram que conseguiram superar dificuldades e a resistência inicial que tinham em relação às novas tecnologias, advindas da falta de familiaridade com elas em seu cotidiano e de uma postura tradicional oriunda de uma educação também tradicional. A disciplina, então, permitiu que elas entrassem em contato com essas tecnologias, aprendessem a utilizá-las também para fins pedagógicos e se surpreendessem com o que conseguiriam realizar:

\section{Excerto 22 - Participante A10}

Não foi um processo fácil, o de aprender a lidar com a modernidade digital em nossa prática docente, até porque para muitos de nós o que foi ensinado era novo e demonstrava o quanto estávamos despreparados para a realidade virtual. Todo o material estudado ao longo do ano também nos fez perceber o quão pouco havíamos pensado sobre o assunto, pois seguindo os padrões em que fomos educados, acreditávamos que um giz, um quadro negro e um bom material didático seriam o suficiente para atingir o nosso objetivo de ensinar.

\section{Excerto 23 - Participante A14}

No início das atividades tive um pouco de dificuldade, mas foi só começar que verifiquei que os alunos têm razão em gostar tanto de computador, pois atrai não só os jovens como também os adultos. Atividades mediadas pelo computador são envolventes, desafiadoras e colaborativas. Essas atividades serviram como base de reflexão para futuros planos de aulas usando essas ferramentas como apoio. 


\section{Excerto 24 - Participante A8}

Ao iniciar este projeto, pensei sinceramente que não fosse capaz de acompanhar a contento essa matéria, na medida em que, como disse, sou bastante tradicional e resistente a toda novidade, a exemplo de outras pessoas da minha idade. Entretanto, tudo indica que meus mitos e minhas resistências estão se exaurindo pouco a pouco. Quão grande está sendo minha surpresa, dia a dia, ao descobrir que sou capaz de compreender e de atuar como um agente criativo, como quando criei um blog com o grupo e depois um só meu, que venho atualizando constantemente, ou ainda, quando salvei minha voz em um podcast. Confesso que fiquei muito orgulhosa da minha performance!!

Embora essa disciplina refira-se a um curso de formação inicial de professores, acreditamos que resultados semelhantes podem ser alcançados também em cursos de formação continuada, promovendo o contato com o uso de novas tecnologias e possibilitando que professores já em serviço, que tenham tido uma formação tradicional e estejam desatualizados em relação a esse uso (e, por isso, se sintam inseguros, desconfiados ou pessimistas), possam dar um primeiro passo para transpor essa barreira inicial.

\section{Considerações finais}

Por meio da análise aqui apresentada, nota-se que a maior parte dos participantes envolvidos na pesquisa avalia a experiência na disciplina como positiva, uma vez que eles percebem a importância da reflexão sobre o uso de novas tecnologias no ensino e aprendizagem de línguas na realidade tecnológica em que vivemos.

Uma disciplina redirecionada para essa discussão durante todo um ano do curso de Letras, enfatizando a relação contínua entre as atividades realizadas e as práticas em contextos de estágio, gerou um espaço para que alguns participantes, pelo menos, entrassem em contato com esse tópico, reconhecessem sua importância e iniciassem uma pequena reflexão sobre questóes que envolvem o uso de novas tecnologias na educação, tais como: o papel do professor nessa nova realidade, a importância de se considerar o contexto e o aluno, e avaliar o uso da nova tecnologia. Ressaltamos, contudo, que estamos atentos para o fato de que o número de participantes que mencionaram esses tópicos é pequeno.

A maioria dos participantes, ainda, reconhece o impacto que a disciplina causou em suas formações e, apesar de parecer haver uma tendência de 
polarização na visão dos participantes, acreditamos que a prática em contexto real pode ter sido uma contribuição inicial para a percepção de desvantagens e vantagens no uso de novas tecnologias e, por consequência, o início de um caminhar em direção à despolarização.

Posicionamo-nos, assim, ao lado daqueles que sugerem a institucionalização da formação tecnológica de futuros professores através de uma disciplina, nos cursos de graduação, que possibilite que se reflita sobre novas tecnologias e sobre as exigências educacionais de uma sociedade em processo de digitalização.

\section{Referências bibliográficas}

BAX, S. Call- Past, present and future. System, v.31, p.13-28, 2003.

BAX, S. Normalisation revisited: the effective use of technology in language education. International Journal of Computer-Assisted Language Learning and Teaching, v.1, n.2, p.1-15, 2011.

BOHN, V. C. R. Comunidades de prática na formação docente: aprendendo a usar ferramentas da Web 2.0. 2010. 158 f. Dissertação (Mestrado em Linguística) Universidade Federal de Minas Gerais, Belo Horizonte, 2010.

BRAGA, D. B; COSTA, L. A. O computador como instrumento e meio para o ensino/aprendizagem de línguas. Trabalhos em Linguistica Aplicada, Campinas, v.36, p.61-79, 2000.

BURNS, A. Analysing action research data. In: BURNS, A. Collaborative Research for English Language Teachers. Cambridge: Cambridge University Press, 1999. p.152-180.

BUZATO, M. O letramento eletrônico e o uso de computadores no ensino de lingua estrangeira: contribuições para a formação de professores. 2001. $188 \mathrm{f}$. Dissertação (Mestrado em Linguística) - IEL, Unicamp, Campinas, 2001.

EGBERT, J. Learning in context: Situating language teacher learning in CALL. In: HUBBARD, P; LEVY, M. (Ed.). Teacher education in CALL. John Benjamins: Amsterdam, 2006.

HUBBARD, P; LEVY, M. The scope of CALL education. In: HUBBARD, P; LEVY, M. (Ed.). Teacher education in CALL. John Benjamins: Amsterdam, 2006. IMBERNOM-PEREIRA, G. Letramento digital e professores de LE: formação para o uso das novas tecnologias em sala de aula. 2009. $234 \mathrm{f}$. Dissertação (Mestrado em Linguística) - Universidade Federal de São Carlos, São Carlos, 2009. 
KESSLER, G. Assessing CALL teacher training: What are we doing and what could we do better? In: HUBBARD, P; LEVY, M. (Ed.). Teacher education in CALL. John Benjamins: Amsterdam, 2006.

MATTOS, A. M. A. Novos letramentos, ensino de língua estrangeira e o papel da escola pública no século XXI. Revista X, v.1, p.33-47, 2011.

MOTTERAM, G.; STANLEY, G. Preface: Special Issue on Web 2.0 and the Normalization of Call. International Journal of Computer-Assisted Language Learning and Teaching, v.1, n.2, p.1-15, 2011.

PAIVA, V. L. M. O. de. A tecnologia na docência em línguas estrangeiras: convergências e tensões. In: DALBEN, A.; DINIZ, J.; LEAL, L.; SANTOS, L. (Org.). Convergências e tensóes no campo da formação e do trabalho docente. Belo Horizonte: Autêntica, 2010.

PAIVA, V. L. M. O. de. A formação do professor para uso da tecnologia. In: SILVA, K. A.; DANIEL, F. G. de; KANEKO-MARQUES, S. M.; SALOMÃO, A. C. B. (Org.). A formação de professores de línguas: novos olhares - Volume II. Campinas: Pontes, 2012.

PETERS, M. Developing computer competencies for pre-service language teachers: Is one course enough? In: HUBBARD, P; LEVY, M. (Ed.). Teacher education in CALL. John Benjamins: Amsterdam, 2006.

PRENSKY, M. Digital Natives, Digital Immigrants. On the Horizon, v. 9, n. 5, 2001. Disponível em: <http://www.marcprensky.com/writing/prensky\%20\%20 digital\%20natives, \%20digital\%20immigrants\%20-\%20part1.pdf>. Acesso em 17 nov. 2011.

REINDERS, H. Technology and second language teacher education. In: BURNS, A.; RICHARDS, J. The Cambridge Guide to Language Teacher Education. Cambridge: Cambridge University Press, 2009.

SANTOS, R. M. As tecnologias e o ensino de inglês no século XXI: reflexos na formação e atuação do professor. 2009. 147 f. Dissertação (Mestrado em Educação Tecnológica) - CEFET, Belo Horizonte, 2009.

SILVA, P. R. B. S. Repensando o papel do professor de inglês a partir da inserção das tecnologias na educação. In: III Congresso Internacional da ABRAPUI, 2012, Florianópolis. Anais... Florianópolis: Universidade Federal de Santa Catarina, 2012.

SMAGORINSKY, P.; COOK, L. S.; JOHNSON, T. S. The Twisting Path of Concept Development in Learning to Teach. Teachers College Record, v.105, n.8, p.1399-1436, 2003. 
SOUZA, P. N.; SILVA, E. L. A.; SAITO, F. S. Letramento digital na formação inicial dos graduandos de Letras da UFJF para o uso do computador no ensinoaprendizagem de língua estrangeira. In: III Encontro Nacional sobre Hipertexto, 2009, Belo Horizonte. Anais... Belo Horizonte: CEFET, 2009.

VIEIRA, A. A. S. Integração de webtecnologia em atividade de ensino: do Proinfo integrado à aula de língua inglesa. Contexturas, v. 17, p. 95-112, 2010.

VIEIRA, A. A. S. Integração de tecnologias e webtecnologias no ensino de língua inglesa: concepções teóricas, crenças e interação na prática docente. Tese (Doutorado em Estudos Linguísticos) - Instituto de Biociências, Letras e Ciências Exatas (UNESP), São José do Rio Preto, 2012.

WARSCHAUER, M. A developmental Perspective on Technology in Language Education. Tesol Quarterly, v.36, n.3, 2002.

WARSCHAUER, M. Technological change and the future of CALL. In: FOTOS, S.; BROWN, C. New Perspectives on CALL for Second and Foreign Language Classrooms. Mahwah: Lawrence Erlbaum Associates, 2004.

Data de recebimento: 30/01/2014. Data de aprovação: 10/04/2014. 
